\title{
85697 - CONTRIBUIÇÕES DE UM PROGRAMA DE EXERCÍCIOS MULTICOMPONENTES SOBRE A CAPACIDADE FUNCIONAL DE IDOSOS
}

\author{
Pôster - Gerontologia
}

Marcos Antônio Silveira da Costa / Costa, MA / Universidade Federal do Rio Grande do Sul; Ângela Ghileni Pena / Pena, AG / Universidade Federal do Rio Grande do Sul

Introdução: O processo de envelhecimento provoca alterações funcionais que podem comprometer a marcha e o equilíbrio de idosos, o que afetam diretamente a capacidade funcional2,3,4. Um programa de exercícios multicomponentes têm demonstrado reduzir quedas e melhorar a capacidade funcional de idosos. No entanto, a combinação ideal de exercícios de força, equilíbrio, velocidade e agilidade precisam ser mais investigados. Objetivo: Verificar os efeitos de um programa de exercícios multicomponentes sobre a capacidade funcional de idosos. Métodos: Foi realizado um estudo observacional a partir de informações de prontuários de 24 idosos que frequentavam um centro de exercícios terapêuticos, 2 vezes por semana, localizado na cidade de Porto Alegre. A bateria de testes Short Physical Performance Battery (SPPB) era usada rotineiramente antes e após 3 meses do programa de exercícios multicomponentes que incluía fortalecimento, treino de equilíbrio e velocidade de marcha. Foi utilizada a estatística descritiva - distribuição absoluta e relativa (n - \%), média, mediana e desvio padrão. A distribuição de dados ocorreu pelo teste de Kolmogorov-Smirnov. A comparação ocorreu pelo teste t-Student e o teste de Wilcoxon. Foi utilizado o software SPSS 20.0, e o nível de significância foi de 5\%. O projeto foi aprovado pelo Comitê de Ética em Pesquisa da Universidade Federal do Rio Grande do Sul, sob nํㅜ․472.393. Resultados: $\mathrm{Na}$ análise parcial do SPPB, o teste de equilíbrio apresentou aumento significativo $(p=0,001)$ de 1,2 pontos. Para velocidade da marcha, houve um aumento significativo $(\mathrm{p}=0,003)$ de 0,5 pontos. $O$ teste de força apresentou um aumento significativo $(p=0,001)$ de 1,3 pontos. No escore total do SPPB, houve diferença significativa $(\mathrm{p}<0,001)$ entre a média no Pós-intervenção $(11,5 \pm 0,9)$ e a avaliação Pré $(8,6 \pm 2,5)$. Conclusões: Este estudo demonstrou que o programa de exercícios multicomponentes realizado gerou um aumento da capacidade funcional de idosos.

Palavras-chave: Envelhecimento. Exercícios em Circuitos. Atividade Motora. 